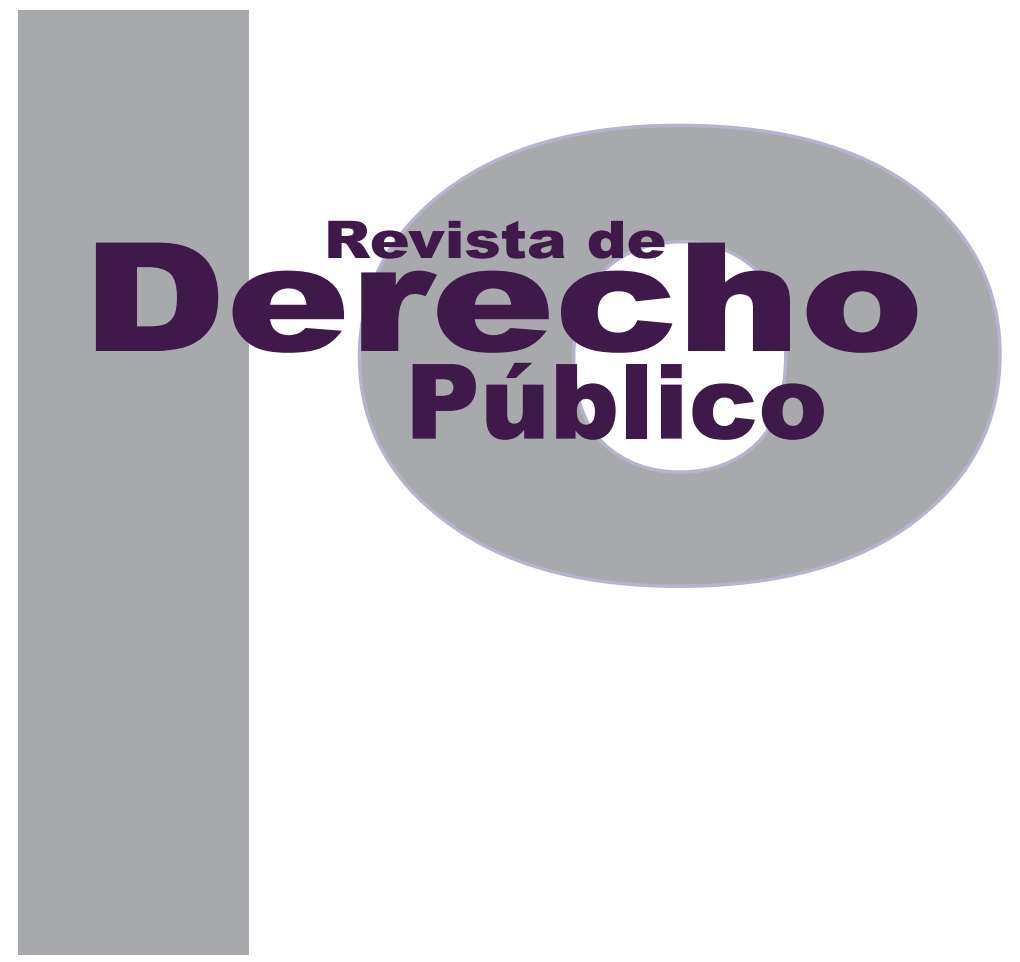

\title{
EL ABANDONO DEL CARGO - DOCENTES. UNA MIRADA DESDE EL PRINCIPIO DE LEGALIDAD
}

AleXANDER LóPEZ QUIROZ

Artículo de reflexión

DOI: http://dx.doi.org/10.15425/redepub.34.2015.22

Universidad de los Andes

Facultad de Derecho

Revista de Derecho Público N. ${ }^{\circ} 34$

Enero - Junio de 2015. ISSN 1909-7778 


\section{El abandono del cargo - docentes. Una mirada desde el principio de legalidad Resumen}

En el presente trabajo se trata de determinar si el abandono del cargo constituye falta disciplinaria para los docentes, pero no se contempla a los docentes universitarios.

Las normas que describían el abandono del cargo para los docentes fueron derogadas. De manera expresa la definición de abandono del cargo contenida en el Decreto 2277 de 1979, y la de la misma falta disciplinaria consagrada en el Decreto 1278 de 2002 fue declarada inexequible por la Corte Constitucional colombiana en la sentencia C-734 de 2003, con ponencia del magistrado Álvaro Tafur, con lo cual surge un vacío normativo.

Palabras clave: abandono del cargo, derecho disciplinario.

\section{The abandonment of teaching post. A view from the legality principie}

\section{Abstract}

The question is if the dereliction of duty constitutes a disciplinary offense for teachers. The rules describing the dereliction of duty for teachers were abolished: so expresses the definition of dereliction of duty in Decree 2277 of 1979, and the definition of the same disciplinary offense enshrined in Decree 1278 of 2002 was declared unconstitutional by the Colombian Constitutional Court; a regulatory vacuum arises.

Keywords: abandonment of office, disciplinary law.

\section{O abandono do cargo - docente. Um olhar desde o princípio de legalidade Resumo}

0 presente trabalho trata de determinar se o abandono do cargo constitui falta disciplinar para os docentes, mas os docentes universitários não são contemplados.

As normas que descreviam o abandono do cargo para os docentes foram derrogadas. De maneira expressa, a definição de abandono do cargo contida no Decreto 2277 de 1979 e a da mesma falta disciplinar consagrada no Decreto 1278 de 2002 foram declaradas inexequíveis pela Corte Constitucional colombiana na sentença C-734 de 2003, com informe do magistrado Álvaro Tafur, com o qual surge um vazio normativo.

Palavras-chave: abandono do cargo, direito disciplinar. 


\title{
El abandono del cargo - docentes. Una mirada desde el principio de legalidad*
}

\author{
Alexander López Quiroz ${ }^{* *}$
}

\section{SUMARIO}

Introducción - I. ABANDONO INJUSTIFICADO DEL CARGO - II. ERROR DE APLICACIÓN NORMATIVA ENTES INVESTIGADORES - III. ABANDONO DEL CARGO DOCENTES - IV. CONCLUSIÓN - Referencias.

* Cómo citar este artículo: López Quiroz, A. (Junio, 2015). El abandono del cargo - docentes. Una mirada desde el principio de legalidad. Revista de Derecho Público, 34. Universidad de los Andes (Colombia).

** Abogado. Magíster en derecho constitucional; especialista en derecho disciplinario, derecho público, derecho ambiental. Profesor de la Universidad del TOlima CREAD Mocoa. 
Introducción

Los docentes son servidores públicos de régimen laboral especial; tienen su propia carrera (la docente), diferentes criterios de evaluación y su particular régimen de pensiones; se desempeñan en el único servicio público esencial y derecho fundamental que puede realizar paros sindicales, y en el Código Disciplinario Único (CDU) se los ha igualado a los demás servidores públicos del Estado. Los docentes de educación superior no son regulados por el CDU, y los vinculados con universidades públicas son servidores públicos a quienes en lo disciplinario aplican los estatutos y reglamentos de la respectiva universidad, los que obviamente deben respetar la Constitución Política y los tratados de derechos humanos ratificados o no por Colombia, de conformidad con los mandatos expresos de los artículos 93 y 94 supra legales.

El régimen jurídico de los docentes definió de manera clara, especial y específica, qué es el abandono del cargo, y lo hizo a través del artículo 46 del Decreto 2277 de 1979, norma derogada por el artículo 43 del Decreto 1278 de 2002. Las preguntas que se pretende responder son: ¿es típica la conducta disciplinaria denominada abandono injustificado del cargo?, ¿se encuentra vigente la falta disciplinaria denominada abandono injustificado del cargo para los docentes?

Las normas citadas decían lo siguiente:

Decreto 1278/2002. Artículo 43. Abandono del cargo. El abandono del cargo se produce cuando el docente sin justa causa deja de concurrir al trabajo; cuando no reasume sus funciones al vencimiento de una licencia, una comisión, un permiso o las vacaciones reglamentarias; cuando en caso de renuncia, hace dejación del cargo antes de que se le autorice para separarse del mismo o antes de transcurrido un mes después de presentada, o cuando no asume el cargo dentro de los cinco (5) días hábiles siguientes a la fecha en que se le comunique un traslado.

El abandono del cargo conlleva la declaratoria de vacancia del mismo previo un proceso sumario en el que se garantice el derecho a la defensa. A su vez, la autoridad debe iniciar el correspondiente proceso disciplinario y proceder a la exclusión del Escalafón Docente.

Decreto 2227/79. Artículo 47. Abandono del cargo. El abandono del cargo se produce cuando el docente sin justa causa no reasume sus funciones dentro de los tres días siguientes al vencimiento de una licencia, una comisión o de las vacaciones reglamentarias; cuando deja de concurrir al trabajo por tres (3) días consecutivos; cuando en caso de renuncia, hace dejación del cargo antes de que se le autorice para separarse del mismo o antes de transcurridos quince (15) días después de presentada y cuando no asume el cargo dentro de los diez (10) días hábiles siguientes a la fecha en que se le comunique un traslado. En estos casos la autoridad nominadora sin concepto previo de la respectiva Junta de Escalafón, presumirá el abandono de cargo y podrá decretar la suspensión provisional del docente, mientras la Junta decide sobre la sanción definitiva de acuerdo con los plazos establecidos en el artículo 53 del presente Decreto. 
El abandono del cargo para docentes no se encuentra descrito en el sistema jurídico vigente, como se verá en esta mirada sucinta al tema respecto de los servidores públicos en general, de conformidad con el cDu.

El presente trabajo es jurídico, y en él se utilizó la metodología de investigación documental cualitativa.

\section{ABANDONO INJUSTIFICADO DEL CARGO}

La doctrina en materia disciplinaria ${ }^{1}$ no ha abordado este tema desde la perspectiva de la existencia o no del tipo disciplinario aplicable a los docentes, por ello este estudio se limitará al campo normativo y jurisprudencial.

El abandono del cargo se ha establecido en numerosas normas. Para la rama ejecutiva se determinó en el Decreto 2400 de 1968, y el artículo 48 numeral 55 del cDu define el abandono injustificado del cargo, función o servicio como falta gravísima: la tipificación de esta falta disciplinaria de naturaleza gravísima exige una clara concepción de lo que debe entenderse por abandono injustificado del cargo, función o servicio.

La Corte Constitucional al declarar exequible esta disposición, estableció claramente en la sentencia C-769 de 1998, de la que fue ponente el magistrado Antonio Barrera Carbonell, lo que

$1 \quad$ No se pretende incurrir en adanismo en esta materia, pero en la doctrina nacional no encontré bibliografía sobre el abandono del cargo por parte de docentes como conducta atípica disciplinaria, sin embargo puede existir. debe entenderse por abandono injustificado del cargo o del servicio:

Abandonar el cargo, o el servicio, implica la dejación voluntaria definitiva y no transitoria de los deberes y responsabilidades que exige el empleo del cual es titular el servidor público. En consecuencia, dicho abandono se puede presentar, bien porque se renuncia al ejercicio de las labores o funciones propias del cargo, con la necesaria afectación de la continuidad del servicio administrativo, o bien porque se deserta materialmente del cargo al ausentarse el servidor del sitio de trabajo y no regresar a él para cumplir con las labores asignadas, propias del cargo o del servicio. Corolario de lo anterior es que el abandono debe ser injustificado, es decir, sin que exista una razón o motivo suficiente para que el servidor se exima de la responsabilidad de cumplir con las funciones propias del cargo o del servicio. Ello es así, porque de ser justificado el abandono del cargo o del servicio desaparece la antijuridicidad del hecho y, por consiguiente, la falta disciplinaria.

De manera tal que atendiendo lo dicho por la rectora de nuestra Carta Política y la doctrina, huelga concluir que la ilicitud sustancial de esta falta disciplinaria se encuentra en la dejación voluntaria, definitiva y no transitoria de los deberes y responsabilidades que exige el empleo del cual es titular el servidor público; significa ello que no habrá abandono del cargo o del servicio como falta gravísima, cuando el servidor se reincorpora luego de una ausencia transitoria.

Probatoriamente hablando, conforme a los ingredientes normativos del tipo disciplinario materia de estudio, será necesario establecer en 
grado de certeza que el abandono del cargo, función o servicio es injustificado, es decir, que desborda los límites de lo correcto, de lo debido, de cómo corresponde actuar a todo servidor público, realizando siempre el interés general; de modo que es injustificado todo abuso del ejercicio de funciones, del cargo o de servicios que le corresponde prestar al servidor público.

De otra parte, cuando el tipo disciplinario se refiere al abandono de la función lo hace para señalar que los particulares que eventualmente ejercen función pública, en lo que tiene que ver con esta, son destinatarios de la falta disciplinaria gravísima que nos ocupa, por el abandono injustificado de esa función.

El juez u operador disciplinario, a la hora de imputar esta falta, deberá tener en cuenta que los particulares destinatarios de la ley disciplinaria en los términos de los artículos 52, 53 y 55 de la Ley 734 de 2002, solo responderán de las faltas gravísimas expresamente establecidas en el artículo 55, entre las que se encuentra el abandono injustificado de la función pública, acorde con lo establecido en el numeral 11.

De manera tal que tratándose de un particular que deba responder por esta falta gravísima, la imputación se hará por vía del numeral 11 del artículo 55 ídem, y no utilizando el dispositivo disciplinario materia del cual nos ocupamos, es decir, el numeral 55 del artículo 48.

En consecuencia, realizada esta falta gravísima bajo la modalidad dolosa, ameritará una sanción de destitución e inhabilidad mínima de diez años y máximo de veinte. Si el abandono no es definitivo, la falta podrá ser calificada de grave o leve, según la naturaleza y entidad de la infracción del deber (art. 34-2 Ley 734 de 2002).

\section{ERROR DE APLICACIÓN NORMATIVA ENTES INVESTIGADORES}

Los investigadores disciplinarios al tratar el abandono del cargo de los docentes vienen sustentando la acusación disciplinaria sobre la base de lo establecido en el art. 126 del Decreto 1950 de 1973, y afirman que dicha conducta se tipifica y se sanciona bajo el numeral 55 del art. 48 del cDu. Como se sabe, la mayoría de tipos disciplinarios o descripciones típicas disciplinarias son normas en blanco o abiertas, es decir, hay que remitirse a otra norma para determinar lo que constituye la falta disciplinaria.

El cDu no establece qué constituye el abandono del cargo por parte de los docentes ni de los servidores públicos en general. Inicialmente, en el artículo 47 del Decreto 2277 de 1979 se estableció cuándo se producía el abandono del cargo por los docentes; posteriormente, en el Decreto 1278 de 2002 que derogó el Decreto 2277 se describe el abandono del cargo, y este (el D. 1278) fue declarado inexequible por la Corte Constitucional, es decir, la norma que explicaba o consagraba la descripción típica del abandono del cargo de los docentes desapareció del marco jurídico vigente.

Ante este vacío normativo los investigadores disciplinarios de los docentes vienen aplican- 
do normas de los empleados en general, esto es, el Decreto 1950 de 1973, reglamentario del Decreto-ley 2400 de 1968, a pesar de que los docentes tienen su propio régimen.

Esta actuación, que se constituye en un pequeño olvido de los investigadores disciplinarios, está permitiendo la analogía en un proceso sancionatorio, situación que solo puede calificarse de absurda, injusta e ilegal.

El Decreto 2400 de 1968, según reza en su encabezado, modifica "las normas que regulan la administración del personal civil y se dictan otras disposiciones".

El Decreto 1950 de 1973 reglamenta, entre otros, el Decreto-ley 2400 de 1968 y otras normas sobre administración del personal civil.

Es evidente, por decir lo menos, que esta norma está dirigida a los servidores públicos en general, es decir a aquellos que no son docentes, dado que estos últimos tienen un régimen especial y su situación administrativa es diferente a la de los demás empleados de la rama ejecutiva.

Los docentes se regulaban por el Decreto 2277 de 1979, norma que restablecía la carrera docente y consagraba el procedimiento disciplinario y las sanciones a ellos aplicables; además, tienen su propio fondo de cesantías creado por la Ley 91 de 1989; son servidores públicos de régimen especial, situación jurídica que los entes investigadores vienen desconociendo totalmente al afirmar con convencimiento y de manera obesa que el abandono del cargo por los docentes se rige por el Decreto 1950 de 1973, en lo cual la negligencia es evidente, la ignorancia es palmaria y el error es rotundo, dado que la descripción legal de dicha conducta no existe debido a la declaratoria de inexequibilidad por parte de la Corte Constitucional colombiana del artículo 43 del Decreto 1278 de 2002 (sentencias C-734 de 2003 y C-1157 de 2003).

Pero no sobra advertir y recordar lo establecido en el Decreto 2277 de 1979, artículo 47, supra.

El derecho disciplinario es sancionador y como tal no es posible la aplicación analógica de otras normas para establecer sanción disciplinaria.

La garantía de prohibición de la analogía constituye un pilar de todo Estado social y democrático de derecho, encontrándose recogida en el artículo 29, inciso segundo, que contempla el principio de legalidad que exige la existencia de la ley al hecho. Igualmente, en los principales instrumentos del derecho internacional de los derechos humanos (Declaración Universal de Derechos Humanos, artículo $11^{\circ}$, numeral 2; Convención Americana sobre Derechos Humanos, artículo $9^{\circ}$; Pacto Internacional de Derechos Civiles y Políticos, artículo $15^{\circ}$ ).

Cabe destacar que el principio de prohibición de analogía se aplica no solo a los tipos penales (supuestos de hecho y consecuencias jurídicas) previstos en la parte especial del Código Penal, sino también a aquellos en los que la parte general comprenda preceptos que amplíen la imputación penal, como es el caso de la tentativa, la coautoría y la participación. 
En sentencias C-739/00 y C-181/02 la Corte Constitucional colombiana, fundada en el art. 29 supra legal, se refirió a la prohibición de la aplicación de la analogía en derecho penal:

Es claro que en la norma superior citada, el Constituyente de 1991 consagró de manera expresa el denominado principio de legalidad, "nullum crimen, nulla poena sine lege", principio tradicionalmente reconocido y aceptado como inherente al Estado democrático de derecho, sobre el cual se sustenta la estricta legalidad que se predica del derecho penal, característica con la que se garantiza la no aplicación de la analogía jurídica en materia penal, la libertad de quienes no infringen la norma, y la seguridad para quienes lo hacen de que la pena que se les imponga lo será por parte del juez competente, quien deberá aplicar aquélla previamente definida en la ley.

La aplicación de la analogía que realizan los investigadores disciplinarios en el caso de abandono injustificado del cargo por parte de los docentes no solo es ilegal e injusta, sino que de acuerdo con este último acápite es atípica.

De otro lado, el Código Penal colombiano en el art. 6 establece la aplicación de la analogía en materias permisivas:

ARTículo 6o. legalidad. Nadie podrá ser juzgado sino conforme a las leyes preexistentes al acto que se le imputa, ante el juez o tribunal competente y con la observancia de la plenitud de las formas propias de cada juicio. La preexistencia de la norma también se aplica para el reenvío en materia de tipos penales en blanco.
La ley permisiva o favorable, aun cuando sea posterior se aplicará, sin excepción, de preferencia a la restrictiva o desfavorable. Ello también rige para los condenados.

La analogía solo se aplicará en materias permisivas.

Además de lo anterior, y con fundamento en lo ordenado en el art. 21 del CDu, la que se denomina analogía in malam partem no es aplicable tampoco en el proceso disciplinario:

ART. 21.- Aplicación de principios e integración normativa. En la aplicación del régimen disciplinario prevalecerán los principios rectores contenidos en esta ley y en la Constitución Política. En lo no previsto en esta ley se aplicarán los tratados internacionales sobre derechos humanos y los convenios internacionales de la olT ratificados por Colombia, y lo dispuesto en Ios códigos Contencioso Administrativo, Penal, de Procedimiento Penal y de Procedimiento Civil en lo que no contravengan la naturaleza del derecho disciplinario.

Ante el vacío del cDu es aplicable lo ordenado en el Código Penal, que de manera expresa prohíbe la analogía in malam partem, es decir, la aplicación del Decreto 1950 de 1968 es ilegal y arbitraria (CConst., sentencias C-417/93 y c-310/97.

La Corte Constitucional en sentencia C-1189 de 2005, en demanda de inconstitucionalidad contra el literal i) del artículo 41 de la Ley 909 de septiembre 23 de 2004 "Por la cual se expiden normas que regulan el empleo público, la carrera administrativa, gerencia pública y se dic- 
tan otras disposiciones", ratificó lo dicho en la sentencia C-769 de 1998, al indicar que tal ausencia del elemento de la tipicidad no tiene ocurrencia en la norma demandada, pues resulta claro que esta determina que la conducta sancionable es el abandono injustificado del cargo, el cual como lo dijo la Corte, siempre debe ser injustificado.

Para los servidores públicos que no son docentes, la Corte Constitucional exige para tipificar el abandono del cargo la dejación permanente de este.

\section{ABANDONO DEL CARGO - DOCENTES}

El abandono del cargo de los docentes, como ya se expuso, se tipificó en el artículo 47 del Decreto 2277 de 1979 y en el artículo 43 del Decreto 1278 de 2002 que derogó el anterior y fue declarado inexequible por la Corte Constitucional en sentencia C-734 de 2003.

En sentencia C-1189 de 2005, la Corte Constitucional al analizar la constitucionalidad del artículo 41 de la Ley 909 de 2004, estableció con claridad la diferencia entre el abandono del cargo como causal de retiro del servicio (declaratoria de vacancia) y como falta disciplinaria:

De esta manera, al igual que en aquella oportunidad, estima esta Corporación que la norma no tiene una proyección disciplinaria ni constituye una sanción que se enmarque en dicho ámbito. Como se planteó en líneas precedentes del presente fallo, este Tribunal Constitucio- nal encuentra que el retiro del servicio del empleado que incurra en abandono del cargo es una medida administrativa consecuente con los principios de igualdad, moralidad, eficacia, economía, celeridad, imparcialidad y publicidad (C.P. art. 209) que rigen la administración pública, en tanto la misma debe contar con la posibilidad de proveer rápidamente un cargo que ha sido abandonado, para que un funcionario entre a cumplir las labores idóneamente, a fin de evitar traumatismos en la marcha de la administración. El proceso disciplinario, por el contrario, estaría dirigido, principalmente, a establecer la responsabilidad individual del funcionario, a fin de imponerle la sanción respectiva.

(...)

41.- No cabe duda que en el ordenamiento jurídico colombiano ha sido constante y reiterada la consagración del abandono del cargo como causal autónoma de retiro del servicio para los empleados de la administración pública. Lo anterior, en atención a la necesidad de hacer más flexible y expedita la separación del cargo de aquellos empleados cuya conducta configure abandono del mismo, en detrimento del normal desempeño de las actividades que debe desarrollar la entidad. Allí precisamente encuentra justificación esta medida, pues no se puede perder de vista que la función administrativa debe tender al logro de los fines esenciales del Estado, regidos, entre otros, por los principios de eficiencia, eficacia y celeridad.

42.- No obstante, es de vital importancia recordar que la decisión de retiro del servicio de un empleado público tiene lugar mediante un acto administrativo de carácter particular y concreto para cuya expedición debe cumplirse el proce- 
dimiento establecido en el Código Contencioso Administrativo, esto es, que la actuación que de oficio inicie la administración, con el fin de retirar del servicio a un empleado - sea este de carrera o de libre nombramiento y remoción-, le debe ser comunicada, para efectos de que este pueda ejercer su derecho de defensa, al ser oído por la autoridad administrativa competente, así como para contar con la oportunidad de aportar y controvertir las pruebas que le sean adversas.

De lo expuesto por la Corte Constitucional en la sentencia C-1189 de 2005 se deducen con claridad los siguientes aspectos:

a) El abandono del cargo es una causal autónoma de retiro del servicio, tal como ha sido consagrada a lo largo del ordenamiento jurídico colombiano (Decreto 1950 de 1973, Decreto-ley 2400 de 1968, Decreto-ley 3074 de 1968, Ley 27 de 1992, Ley 443 de 1998 y Ley 909 de 2004).

b) Existen diferencias entre el régimen disciplinario, entendido como una modalidad de derecho sancionatorio, y el régimen de carrera administrativa, incluyendo el retiro del servicio de los empleados de libre nombramiento y remoción, el cual tiene como fundamento la selección de los mejores servidores y el proceso de evaluación y control de su desempeño. En esa medida, para un servidor, un mismo comportamiento como el abandono del cargo, implica consecuencias negativas en ambos ámbitos, sin que ello implique un doble enjuiciamiento.

c) En el caso específico del literal i, del artículo 41 de la Ley 909 de 2004, teniendo en cuenta la finalidad de la norma, el contexto regulatorio en el que se ubica, la estructura legal y el bien jurídico que se pretende proteger, se concluye que dicho precepto no se encuentra inscrito en el ámbito del derecho disciplinario, sino que pretende regular aspectos de la carrera administrativa y el empleo público.

d) Cualquier decisión de retiro del servicio debe estar mediada por el cumplimiento de un procedimiento administrativo que garantice el debido proceso del afectado, como lo establece el inciso primero del artículo 35 del Código Contencioso Administrativo.

El Consejo de Estado en reiterada jurisprudencia ha sostenido que el abandono del cargo, a partir de la expedición de la Ley 200 de 1995, dejaba de ser una causal autónoma de retiro del servicio, siendo necesario la mediación de un proceso disciplinario para declarar la vacancia del cargo.

En sentencia del 21 de junio de 2001, con ponencia del consejero Nicolás Pájaro Peñaranda, la Sección Segunda del Consejo de Estado, dijo lo siguiente:

Desde la vigencia de la citada ley 200 es evidente para la Sala que la causal de retiro del servicio por abandono del cargo, establecida en el artículo 25 del decreto 2400 de 1968, modificado como ya se dijo, junto con su reglamentación contenida en los artículos 126 a 128 del decreto 1950 de 1973, fueron derogados por aquella ley, para ser gobernado el abandono injustificado del cargo o del servicio por el régimen disciplinario allí establecido, 
en los términos que se dejaron reseñados. Lo anterior determina que la entidad demandada en lugar de emitir el día 22 de enero de 1996 el acto acusado, que retiró del servicio al actor por declaración de vacancia del cargo por abandono, debió proseguir el proceso disciplinario que intentó tramitar el día siguiente, cuando lo oyó en versión libre y espontánea, y que la Sala deba revocar la sentencia apelada, para en su lugar, acceder a las pretensiones de la demanda.

De igual forma, en sentencia del 6 de noviembre de 2003, con ponencia del consejero Alberto Arango Mantilla, señaló:

A partir de la expedición del Código Único Disciplinario (Ley 200 de julio 28 de 1995) "el abandono injustificado del cargo o del servicio" es considerado claramente por el legislador como una falta disciplinaria gravísima. Así se consagró en el numeral $8^{\circ}$ del artículo 25 de la citada ley.

Significa entonces que cuando el servidor público docente no reasume sus funciones dentro de los tres días siguientes al vencimiento de una licencia, comisión o vacaciones reglamentarias; o deje de concurrir al trabajo por 3 días consecutivos; o no concurre al trabajo antes de serle concedida autorización para separarse del servicio o en caso de renuncia antes de vencerse el plazo establecido en el artículo 47 del Decreto 2277 de 1979; o no asume el cargo dentro de los diez (10) días hábiles siguientes a la fecha en que se le comunicó el traslado; las autoridades estarán obligadas a adelantar un proceso disciplinario con el fin de garantizar el debido proceso y el derecho de audiencia y defensa, conforme a las leyes sustantivas y procesales preexistentes a la falta cometida, en los términos establecidos en el artículo 29 de la Constitución Política.

En la sentencia C-341 de 1996 la Corte se refirió al derecho disciplinario en la Constitución, en los siguientes términos:

El derecho disciplinario comprende el conjunto de normas, sustanciales y procesales, en virtud de las cuales el Estado asegura la obediencia, la disciplina y el comportamiento ético, la moralidad y la eficiencia de los servidores públicos, con miras a asegurar el buen funcionamiento de los diferentes servicios a su cargo. Por consiguiente, el sistema normativo que configura dicho derecho regula:

a) Las conductas -hechos positivos o negativos- que pueden configurar falta juzgable disciplinariamente. Es así, como la violación de los deberes, de las prohibiciones o de las inhabilidades o incompatibilidades, a que están sujetos los funcionarios y empleados públicos, es considerado por el respectivo estatuto disciplinario como falta disciplinaria.

b) Las sanciones en que pueden incurrir los sujetos disciplinados, según la naturaleza de la falta, las circunstancias bajo las cuales ocurrió su comisión y los antecedentes relativos al comportamiento laboral.

c) El proceso disciplinario, esto es, el conjunto de normas sustanciales y procesales que aseguran la garantía constitucional del debido proceso y regulan el procedimiento a través del cual se deduce la correspondiente responsabilidad disciplinaria.

En la sentencia C-280 de 1996, al reiterar la naturaleza y finalidad del derecho disciplinario, 
analizadas en diferentes pronunciamientos, dijo la Corte que:

Este es consustancial a la organización política y absolutamente necesario en un Estado de Derecho $\left(\mathrm{CP}\right.$ art. $\left.1^{\circ}\right)$, por cuanto de esta manera se busca garantizar la buena marcha y buen nombre de la administración pública, así como asegurar a los gobernados que la función pública sea ejercida en beneficio de la comunidad y para la protección de los derechos y libertades de los asociados (CP arts. $2^{\circ}$ y 209). Por ello el derecho disciplinario "está integrado por todas aquellas normas mediante las cuales se exige a los servidores públicos un determinado comportamiento en el ejercicio de sus funciones", ya que los servidores públicos no solo responden por la infracción a la Constitución y a las leyes sino también por la omisión o extralimitación en el ejercicio de sus funciones (CP art. $\left.6^{\circ}\right)$.

\section{(...)}

Gran parte de los cometidos del Estado Social de Derecho deben ser realizados por la administración, la cual funda su eficiencia y eficacia en cuanto los pueda traducir en hechos y obras concretos.

\section{(...)}

La administración en dicho Estado ha sido instituida para servir a los altos intereses de la comunidad, lo cual se traduce en el deber de desarrollar actividades concretas de beneficio colectivo para satisfacer las necesidades insatisfechas de esta, mediante el ejercicio de los diferentes poderes de intervención de que dispone. Ello impone la necesidad de que la actividad de los funcionarios estatales se adecue a los imperativos de la eficacia, la eficiencia y la moralidad administrativa. Así se asegura, el adecuado funcionamiento de los servicios estatales, el correcto manejo y la preservación del patrimonio público, y la buena imagen de la administración, la cual gana legitimidad y credibilidad frente a la comunidad.

Se colige de lo anterior que hay unos principios que son comunes al derecho penal y al derecho disciplinario, como lo ha establecido la propia Corte Constitucional colombiana, a saber: "Ios de legalidad, tipicidad, derecho de defensa, irretroactividad, culpabilidad, proporcionalidad, presunción de inocencia, non bis in idem, etc." (Sentencia C-769 de 1998).

El derecho a un debido proceso, garantizado desde el art. 29 de la Constitución Política y el Pacto de San José de Costa Rica, que consagran las garantías sustanciales y procesales que lo integran dándole una connotación de mucha importancia al principio de legalidad, le impone el deber al legislador de determinar las conductas o tipos disciplinarios, en los que debe realizar la descripción típica disciplinaria de manera clara.

La tipicidad cumple con la vital finalidad de garantizar los demás derechos fundamentales, como la libertad y seguridad individual al establecer "en forma anticipada, clara e inequívoca qué comportamientos son sancionados, y de otro, proteger la seguridad jurídica", en palabras de la Corte Constitucional (sentencia C-769 de 1998).

En la misma sentencia se lee lo siguiente:

La Corte, en varias oportunidades ha reconocido que la tipicidad es un principio rector 
en materia disciplinaria. Así, en la sentencia C-417/93 expresó la Corte:

"Las faltas disciplinarias son definidas anticipadamente y por vía general en la legislación y corresponden a descripciones abstractas de comportamientos que, sean o no delitos, enturbian, entorpecen o desvirtúan la buena marcha de la función pública en cualquiera de sus formas, lo que hace que las mismas disposiciones que las consagran estatuyan, también con carácter previo, los correctivos y sanciones aplicables a quienes incurran en aquellas. Según las voces del artículo 124 de la Constitución, "la ley determinará la responsabilidad de los servidores públicos y la manera de hacerla efectiva".

Y en la sentencia C-280/95, expresó:

“... No solo las faltas disciplinarias deben estar descritas en norma previa sino que además, la sanción debe estar predeterminada. Debe haber pues certidumbre normativa previa sobre la sanción a ser impuesta".

Los criterios antes expuestos aparecen reiterados en la sentencia C-310/97 en la cual se dijo:

“... El derecho disciplinario es una modalidad de derecho sancionatorio, por lo cual los principios del derecho penal se aplican, mutatis mutandi en este campo, pues la particular consagración de garantías sustanciales y procesales a favor de la persona investigada se realiza en aras del respeto de los derechos fundamentales del individuo en comento, y para controlar la potestad sancionadora del Estado."

"También ha dicho que "uno de los principios esenciales en materia sancionatoria es el de la tipicidad, según el cual las faltas disciplinarias no sólo deben estar descritas en norma previa sino que, además, la sanción debe estar predeterminada'. Dicho principio está consagrado en nuestra Constitución como parte integrante del debido proceso, pues al tenor del artículo 29 de la Constitución, "nadie podrá ser juzgado sino conforme a leyes preexistentes al acto que se le imputa'".

La conclusión de lo anterior es la necesidad de la existencia de la norma que consagre el complemento de lo tipificado como abandono del cargo; en el caso especialísimo de los docentes, esta descripción fue realizada inicialmente por el Decreto 2277 de 1979, a través del artículo 47 , derogado tácitamente por el artículo 43 del Decreto 1278 de 2002, norma declarada inexequible por la Corte Constitucional colombiana en ejercicio del control abstracto de constitucionalidad, ergo en este momento no existe descripción típica del abandono injustificada del cargo de los docentes.

Bajo la óptica del principio de legalidad reiterado por numerosa jurisprudencia de la Corte Constitucional, misma que ya constituye precedente judicial, no existe la falta disciplinaria denominada abandono injustificado del cargo; y desde la referencia necesaria por la norma en blanco o tipo abierto como lo es el numeral 55 del artículo 48 del cDu, tampoco los docentes pueden ser investigados y mucho menos ser sancionados.

La aplicación analógica de las normas para restringir derechos o su aplicación en procesos penales y sancionatorios no es posible por principio de legalidad, que exige que la ley preexista 
al hecho, que se encuentre debida y claramente descrita, que cobije o sea dirigida a los sujetos específicos.

Como se dijo inicialmente, los docentes son servidores públicos de régimen especial, y como tal se han regido por normas especiales y específicas, y el legislador delegado de igual manera estableció las normas disciplinarias especiales para estos funcionarios. El procedimiento disciplinario quedó unificado para casi todos los servidores públicos con el CDU, pero en el caso de la descripción de algunas faltas disciplinarias estas fueron determinadas por la Ley 115 de 1994, y ahora por el Decreto 1278 de 2002, lo que deja en claro que no le es aplicable a los docentes la descripción típica del abandono del cargo plasmada en el Decreto 1950 de 1973 que rige a los servidores públicos de la rama ejecutiva en general.

\section{CONCLUSIÓN}

La falta disciplinaria "abandono del cargo" no existe para los docentes, hasta tanto el Congreso de la República expida una ley que determine la descripción legal de dicha conducta, es decir, establezca de manera clara e inequívoca en qué consiste el abandono del cargo por parte de un docente, y deberá hacerlo de conformidad con lo decidido por la Corte Constitucional colombiana. En otras palabras, el legislador es quien debe crear el tipo disciplinario para los docentes.

Los docentes no pueden ser investigados $\mathrm{ni}$ sancionados por abandono injustificado del car- go, debido a que dicha falta disciplinaria, consagrada en el CDU, al ser norma en blanco requiere que otra norma determine su descripción legal o explique de manera clara en qué consiste este.

El abandono injustificado del cargo no se encuentra tipificado en Colombia para los docentes.

\section{Referencias}

Código Contencioso Administrativo. Ley 1437 de 2011.

Código Disciplinario Único. Ley 734 de 2002.

Congreso de la República de Colombia. Ley 91 de 1989. Por la cual se crea el Fondo Nacional de Prestaciones Sociales del Magisterio. Recuperado de: http://www.mineducacion. gov.co/1621/articles-85852_archivo_pdf. pdf

Congreso de la República de Colombia. Ley 115 de 1994. Por la cual se expide la Ley general de educación. Recuperado de: http://www. mineducacion.gov.co/1621/articles-85906_ archivo_pdf.pdf

Congreso de la República de Colombia. Ley 200 de 1995. Por la cual se adopta el Código Disciplinario Único. Recuperado de: http://www. procuraduria.gov.co/portal/media/file/codigo2012.pdf

Congreso de la República de Colombia. Ley 734 de 5 de febrero de 2002. Por la cual se expide el Código Disciplinario Único. Re- 
cuperado de http://www.procuraduria.gov. co/guiamp/media/file/Macroproceso\%20 Disciplinario/L-734-02.htm

Congreso de la República de Colombia. Ley 909 del 23 de septiembre de 2004. Por la cual se expiden normas que regulan el empleo público, la carrera administrativa, gerencia pública y se dictan otras disposiciones. Recuperado de: http://www.secretariasenado.gov.co/ senado/basedoc/ley_0909_2004.html

Constituyente. (1991). Constitución Política de Colombia. Bogotá: Editorial Legis.

Consejo de Estado. Sección Segunda. Sentencia del 21 de junio de 2001. C. P.: Nicolás Pájaro Peñaranda.

Consejo de Estado. Sección Segunda. Sentencia del 6 de noviembre de 2003. C. P.: Alberto Arango Mantilla.

Convención Americana sobre Derechos Humanos. Suscrita en la Conferencia Especializada Interamericana sobre Derechos Humanos. (7 al 22 de noviembre de 1969). Convención americana sobre derechos humanos. Pacto de San José. San José, Costa Rica.

Corte Constitucional de Colombia. Sentencia C-417 del 4 de octubre de 1993. M. P.: José Gregorio Hernández. Recuperado de: http://www.corteconstitucional.gov.co/ relatoria/1993/C-417-93.htm

Corte Constitucional. Sentencia C-280 de 25 de junio de 1996. M. P.: Alejan- dro Martínez Caballero. Recuperado de: http://www.corteconstitucional.gov.co/ relatoria/1996/C-280-96.htm

Corte Constitucional. Sentencia C-341 de 5 de agosto de 1996. M. P.: Antonio Barrera Carbonell. Recuperado de: http://www.corteconstitucional.gov.co/ relatoria/1996/C-341-96.htm

Corte Constitucional. Sentencia C-769 de 10 de diciembre de 1998. M. P.: Antonio Barrera Carbonell. Recuperado de: http://www.corteconstitucional.gov.co/ relatoria/1998/C-769-98.htm

Corte Constitucional. (2002). Sentencia C-739 del 10 de diciembre de 2002. M. P.: Jaime Córdoba Triviño. Recuperado de: http://www.corteconstitucional.gov.co/ relatoria/2002/C-739-02.htm

Corte Constitucional. Sentencia C-1157 del 4 de diciembre de 2003. M. P.: Eduardo Montealegre Lynett. Recuperado de: http://www.corteconstitucional.gov.co/ relatoria/2003/c-1157-03.htm

Corte Constitucional. Sala Plena. Sentencia C-734 de 26 de agosto de 2003. M. P.: Álvaro Tafur Galvis. Recuperado de: http:// www.corteconstitucional.gov.co/relatoria/2003/c-734-03.htm

Corte Constitucional. Sentencia C-769 de 2003.

Corte Constitucional. Sentencia C-1189 de 22 de noviembre de 2005. M.P.: Humber- 
to Antonio Sierra Porto. Recuperado de: Presidencia de la República de Colombia. Decrehttp://www.corteconstitucional.gov.co/ to 1950 de 24 de septiembre de 1973. Por relatoria/2005/c-1189-05.htm el cual se reglamentan los Decretos-Leyes 2400 y 3074 de 1968 y otras normas sobre

Ministerio de Educación. Decreto 2277 de septiembre 14 de 1979. Recuperado de: http://www.mineducacion.gov.co/1621/articles-103879_archivo_pdf.pdf administración del personal civil.

Presidencia de la República de Colombia. Decreto 2277 de 14 de septiembre de 1979. Por el cual se adoptan normas sobre el ejer-

Naciones Unidas. (1948). Declaración Universal de Derechos Humanos.

Naciones Unidas. (1966). Pacto Internacional de Derechos Civiles y Políticos.

Presidencia de la República de Colombia. Decreto-ley 2400 de septiembre 19 de 1968. Por el cual se modifican las normas que regulan la cicio de la profesión docente. Recuperado de http://www.mineducacion.gov.co/1621/articles-103879_archivo_pdf.pdf

Presidencia de la República de Colombia. Decreto 1278 de junio 19 de 2002. Por el cual se expide el Estatuto de Profesionalización Docente. administración del personal civil y se dictan otras disposiciones. 